\title{
De um mundo da escola para uma escola do mundo: reflexão sobre meios e sobre fins
}

Carlos Vinicius Oliveira de Moraes

Especialista em Gestão de Processos Comunicacionais pela Escola de Comunicações e Artes da Universidade de São Paulo.

E-mail: vinniciusmoraes@ig.com.br

Já se foram os românticos tempos em que se aguardava ansiosamente para recolher as garrafas deixadas pelo leiteiro na entrada da casa no início de cada dia: uma época em que toda a família se reunia na sala enquanto um dos membros permanecia próximo ao rádio tentando captar sinais com notícias sobre os bravos combatentes brasileiros na Europa em guerra. Pouco mais de meio século depois, a família reunida na sala pôde presenciar ataques de mísseis ocorridos no Oriente, em tempo real, como se assiste a um filme: o sangue, porém, não era cenográfico; disputa com muitas baixas (de militares e civis), cidades arrasadas, tudo acompanhado dos lares de diversas partes do planeta, onde famílias - à primeira vista, por estarem distantes geograficamente - oravam para que um dos comandantes anunciasse sua rendição, pondo fim à barbárie.

A sociedade mudou muito nas últimas décadas, e em velocidade alucinante. Adotaram-se novos conceitos, derrubaram-se tabus. E a escola, um dos principais pilares para a construção de uma sociedade mais justa, fraterna e igualitária, não pode se fechar para o novo, limitando-se a contemplar a história e os feitos passados, mas sim agir no presente, apropriando-se de todos os meios disponíveis para consecução de seus objetivos, formando cidadãos autônomos, críticos e participantes que possam empreender as mudanças necessárias à construção de uma sociedade com relações mais humanas.

Há tantas informações disponíveis, sobre os mais variados assuntos, e que podem ser obtidas do nosso próprio quarto, em segundos. Já se consagrou a afirmação de que vivemos em uma sociedade da informação, o que não quer dizer que possuímos mais conhecimento do que as gerações anteriores: ter informação não significa necessariamente possuir conhecimento.

E a escola, que outrora era a única - ou pelo menos a primeira - fonte de informação para os jovens, adquire novas funções, devendo proporcionar aos 
educandos a capacidade de refletir criticamente sobre as inúmeras mensagens recebidas, a fim de que não aceitem passivamente tudo o que lhes é oferecido, mas examinem e julguem de acordo com valores éticos e morais consagrados, aprendendo a transformar informação em conhecimento.

Iniciamos um novo século vivendo em uma sociedade em que o que vestimos, o que dizemos ou como nos comportamos imediatamente faz com que sejamos associados a determinado grupo social. Uma simples observação ratifica que tudo ao redor nos fala incessantemente, indicando-nos um caminho a seguir, sugerindo-nos preferências, impondo-nos hábitos, referenciando cada passo dado, se nos aproximamos ou nos distanciamos daquilo que é veiculado. São aparelhos de televisão na sala e nos quartos das residências, rádios em casa, no trabalho ou utilizados no percurso entre eles - seja no automóvel ou no discman -, além de outdoors emoldurando as avenidas, letreiros luminosos, cartazes, muros pintados, de modo que nossa mente não pára, processando tantos signos, símbolos e imagens.

Muitos de nossos alunos dedicam mais horas aos novos recursos tecnológicos - consumindo imagens e mensagens - do que às atividades em sala de aula. Os jovens são seduzidos pelas opções dos novos equipamentos e seus acessórios, permitindo que estes lhes roubem quase todo o tempo em que não estão na escola, que poderia - e deveria - ser dedicado a interações mais próximas com outros sujeitos (de mesma faixa etária ou não), o que certamente despertaria nas crianças e adolescentes outras variadas emoções; tempo que se destinaria a brincadeiras e sonhos. É cada vez mais precoce a idade em que as crianças começam a interagir com computadores ou jogos eletrônicos, e muito comum residências em que os aparelhos de televisão, de videocassete e de som são operados por elas, haja vista a inabilidade de alguns adultos para lidar com toda a tecnologia disponível. Essas crianças, ao chegarem à escola, muitas vezes encontram nas salas de aula um cenário no qual são oprimidas durante horas, estando claramente definidos (até mesmo pela disposição física) quem é o ator e quem são os agentes passivos daquela atividade, em que a única cor na cena é a do giz na lousa.

Considerando que pedagogias inclusivas objetivam, além de facilitar o domínio das ciências físicas e sociais, um estudo atento e crítico da tecnologia, ajudando o pleno desenvolvimento das competências dos educandos, não se pode desprezar a facilidade dos jovens em relacionar-se com esses recursos tecnológicos, e o quão encantadora é tal relação. Declarar guerra às tecnologias seria negar a própria contemporaneidade - e os jovens não hesitariam em manifestar sua opção.

A solução para esse desafio é bem mais complexa do que dotar todas as salas de aula de aparelhos de televisão e videocassete, por exemplo: de nada adianta todo o aparato tecnológico sem ações para criar ambientes de aprendizagem que privilegiem a problematização, a atividade reflexiva, a atitude crítica, a capacidade decisória e a autonomia, propiciando a construção do conhecimento por meio de uma atuação ativa, crítica e criativa por parte de alunos e professores. 
Considerando ainda que toda e qualquer ação desenvolvida em espaços educativos envolve pessoas e que a atividade humana é essencialmente comunicativa, educação e comunicação devem somar-se, contribuindo harmoniosamente para a eficácia de todo o sistema.

Muitos professores ainda preferem não ousar, protegendo-se no ambiente da sala de aula. Um exemplo disso é o pequeno número de projetos inter/ trans/multidisciplinares desenvolvidos nos espaços educativos formais. Buscando transformar essa realidade do cotidiano escolar, programas que pretendam colaborar com a formação de cidadãos ativos devem destacar a relevância da comunicação institucional, em seus mais diversos níveis, interna e externamente, com a proposição de ações para facilitar a difusão da informação e a produção de conhecimento no ambiente educativo, criando e fortalecendo verdadeiro ecossistema comunicativo. Ao pensarmos sobre questões e estratégias relacionadas com a promoção do diálogo, torna-se indispensável considerá-lo como todo e qualquer tipo de comunicação verbal, ampliando o sentido do termo, como preconiza Mikhail Bakhtin ${ }^{1}$, tomando-o como ponto central de experiências coletivas.

Nas escolas, muitas questões ainda permanecem sem respostas, principalmente no concernente à inter-relação comunicação/educação, mas o conjunto de reflexões já permite afirmar que, diante da nova realidade histórica da sociedade, serão necessárias mudanças não só de discursos ou atitudes, mas de comportamentos de todos os que convivem em espaços educativos.

Assim, visando à maior compreensão em torno da presença e dos usos das tecnologias da informação na educação, é crucial voltarmos nossa atenção e nossos esforços para ações capazes de responder satisfatoriamente à seguinte demanda: Como podem os sujeitos em espaços educativos apropriar-se das novas linguagens e dos inúmeros recursos audiovisuais disponíveis, utilizando-os de forma democrática e libertadora, transformando os muros ora existentes em "pontes", transcendendo o mero uso das tecnologias como ferramentas ou instrumentos?

\section{NOVAS TECNOLOGIAS, TRANSFORMAÇÕES SOCIAIS E INSTITUIÇÕES ESCOLARES}

Com o avanço das novas tecnologias e diante do conseqüente impacto sobre processos e instituições sociais, ao transformar em todos os níveis as relações humanas, seja em família, seja no trabalho ou no lazer, a sociedade iniciou forte pressão no sistema de educação básica para que essas mudanças sejam por ele mais rapidamente absorvidas, com a incorporação das novas tecnologias como ferramentas pedagógicas a serem utilizadas na formação de um novo tipo de indivíduo, que seja dotado, além de múltiplas habilidades técnicas, de capacidades para a realização de trabalhos em equipe, a fim de aprender constantemente e adaptar-se a situações novas, que são exigências do mundo contemporâneo.
1. BAKHTIN, Mikhail. Marxismo e filosofia da linguagem. São Paulo: Hucitec, 1979 
Fora do ambiente de sala de aula, máquinas e tecnologias estão por toda parte, sendo reconhecidas por alguns até mesmo como escolas paralelas, tal a função desempenhada atualmente pelos veículos de comunicação na produção e na difusão de informações, consagrando novas formas de aprender. Em relação a outros setores da sociedade, a escola caracteriza-se por maior lentidão na incorporação das mudanças, permitindo um distanciamento progressivo entre o discurso didático-pedagógico e as linguagens institucionalmente não-escolares. Um exemplo: ao mesmo tempo em que as instituições escolares ainda não integraram as transformações nos modos de aprender apresentadas pela televisão (veículo com forte e crescente presença na sociedade brasileira nas últimas três décadas, difundindo por todo o território nacional hábitos como, por exemplo, o privilégio a mensagens curtas ou a prática do zapping), oferecem aos alunos modernos laboratórios de informática, com linguagens específicas e recursos midiáticos. Oportuno o alerta de Belloni, segundo o qual "a questão da integração das TIC aos processos educacionais transcende as questões puramente técnicas para se situar no nível da definição das grandes finalidades sociais da educação"².

Todas essas pressões forçam as escolas a repensar seus métodos, em resposta às exigências de um novo tempo. Assim, um dos grandes desafios para as instituições escolares neste século é, não se curvando de forma submissa às necessidades de produção ou às determinações do mercado de trabalho, reafirmar seu compromisso institucional com um ensino que permita um vínculo crítico quanto às novas formas de relação social, nas quais as tecnologias ocupam destacado papel. Além de não apenas privilegiar o domínio das técnicas necessárias para o uso das máquinas, promover ações que visem estabelecer conexões dialógicas entre todos os sujeitos que convivem no espaço escolar, em uma perspectiva de educação para a cidadania plena, "resgatando os ideais de democratização do conhecimento e da informação como instrumentos de emancipação"3.

Há séculos, a preocupação com a ordem e com a disciplina no ambiente escolar determina a distribuição de tempos e espaços nas escolas. Não é mera coincidência seus prédios lembrarem presídios ou hospitais: longos corredores, que facilitam a observação e o monitoramento da circulação de pessoas, com salas distribuídas por ambos os lados. Em cada sala de aula, logo em frente à porta, a mesa e a cadeira reservadas para o professor, e, voltadas para sua direção, todas as cadeiras e mesas destinadas aos alunos da classe (de 30 a 45 por turma, em média, dependendo da instituição e da série). Impossível interagir, mesmo com quem está sentado ao lado, sem ser notado.

Outro fator que aumenta a pressão exercida por alunos e seus familiares sobre a instituição escolar são os programas dos concursos vestibulares, que restringem - chegando quase a eliminar - ações alternativas ao formato convencional de transmissão de conhecimentos, com aulas magistrais de 50 minutos

2. BELLONI, Maria Luiza. O que é mídia-educação. Campinas: Autores Associados, 2001. p. 29. (Polêmicas do Nosso Tempo, 78).

3. Ibid., p. 47 para cada disciplina e avaliações mensuradas exclusivamente por provas e testes feitos individualmente.

Alguns educadores, contudo, começam a perceber - e a permitir - novos modos de equacionar a questão da construção do conhecimento, derrubando 
a barreira da sala de aula convencional com novas práticas: colocam-se como mediadores desse processo para os educandos; modificam atitudes e comportamentos, aproximando-se dos jovens; reconhecem e incorporam às atividades pedagógicas novas formas de aprendizado, esforçando-se para que seus alunos, mais do que memorizar conteúdos, aprendam a aprender; e capacitam para atuações em equipe e para a rápida adaptabilidade diante de novas situações, ocorrência típica das relações de trabalho neste novo século.

\section{OUTRAS LINGUAGENS E "AQUELA CAIXA"}

A escola deverá, necessariamente, mudar sua relação com a mídia. Caberá ao trabalho pedagógico fazer com que os discursos de massa, e em particular a TV, deixem de circular subterraneamente para participarem do processo de formação do leitor crítico.

Eliana Nagamini ${ }^{4}$

São inúmeras as possibilidades de incorporação de material lingüístico proveniente dos meios de comunicação, bastando ao educador estar atento à realidade de seus alunos. Deve-se deixar sensibilizar para captar os discursos recheados de mensagens provenientes das músicas mais executadas nas emissoras de rádio, das cenas dos filmes exibidos no cinema ou na televisão, das tramas das telenovelas, das notícias e reportagens dos telejornais ou de revistas e jornais impressos, dos conteúdos de campanhas publicitárias e, até mesmo, por mais surpreendente que possa parecer, das histórias em quadrinhos, também consideradas meios de comunicação de massa, em função da quantidade impressa e da disposição ao grande público.

Não obstante a maior popularidade do rádio, é a televisão, com sua linguagem complexa, por fundir diferentes instâncias de signos, que atrai, seduz e mantém ligados por mais tempo seus espectadores. Desde sempre, a televisão é movida por interesses estritamente comerciais. Na sociedade do espetáculo, importa menos o que realmente somos ou fazemos do que aquilo que parecemos, disseminando-se um simulacro criado como representação de um mundo naturalmente complexo. Essa construção, porém, mistura-se à realidade, reconfigurando-a ininterruptamente. A relação e a absorção da infinidade de mensagens veiculadas varia a cada receptor, dependendo do meio em que vive, do acesso a outras fontes de informação e entretenimento, entre outras características. Em alguns casos, em decorrência desses fatores, a televisão pode gerar uma leitura deturpada da realidade.

Inconcebível imaginar que um veículo com tamanho poder de penetração, principalmente em países periféricos, nos quais a maior parte da população não pode usufruir de outras formas de lazer e informação, vá adaptar-se aos objetivos desejados pela escola, em detrimento de seus interesses precípuos.
4. NAGAMINI, Eliana. Televisão, publicidade e escola. In: CHIAPPINI, Lígia; CITELLI, Adilson (Coord.). Aprender e ensinar com textos não-escolares. 3 ed. São Paulo: Cortez, 2000. p. 48. 
Assim, os educadores, em vez de repudiar ou desqualificar a importância desse meio nas sociedades pós-modernas, devem afastar estereótipos e preconceitos e tornar a escola um palco privilegiado para sediar discussões indispensáveis, a fim de que todos possam ser capazes de desvendar os segredos e truques da "telinha”, com suas sutis técnicas de sedução e persuasão. Ao desmistificar tal veículo juntamente com os jovens, torna-os aptos a refletir sobre suas escolhas, desenvolvendo o zapping inteligente, com um olhar crítico e atento sobre os conteúdos transmitidos. Aos educadores, ainda, urge livrarem-se de discursos como o de que a televisão somente é capaz de alienar seus espectadores, meros seres passivos encantados por seus matizes, e aceitarem que, independentemente de seus objetivos comerciais e de entretenimento, esse meio é parte integrante do conjunto de experiências de seu público, que aprende com suas mensagens nunca neutras. Este é um ponto fundamental para pedagogias comprometidas com valores morais e éticos e com a formação de cidadãos autônomos e responsáveis, leitores críticos do mundo e capazes de perceber os interesses e as orientações ideológicas contidos nas mensagens veiculadas.

Outro dado relevante é que o processo de recepção de mensagens televisivas não se encerra diante da tela, no momento em que as imagens são exibidas: as informações divulgadas nas produções - sejam telenovelas, reportagens ou outros tipos de programas - pautam a maior parte das discussões subseqüentes, em casa, no trabalho, no clube ou em quaisquer outros espaços de interações sociais. Na escola não é diferente: a peculiaridade, porém, é que os debates sobre a programação televisiva não ocorrem nos momentos formais, ou seja, durante as aulas, mas nos intervalos, pelos corredores, no pátio, na sala dos professores e nos demais locais em que se estabelece o que Citelli define como "discurso subterrâneo" ${ }^{5}$. Não só o conteúdo da grade de programação precisa ser discutido nos espaços educativos, mas também as campanhas veiculadas nos intervalos comerciais, com suas técnicas refinadas em relação ao texto e à imagem, para, em curtíssimo espaço de tempo, deixarem seu recado para os espectadores que se lembrarão dos jingles, dos slogans e das "qualidades" anunciadas dos produtos, quando os virem na gôndola do supermercado ou nas vitrinas das lojas dos centros comerciais. No meio dessa retórica intermitente, muitas vezes sem plena ciência dos acontecimentos, a platéia vai incorporando novas formas de discurso, novas atitudes e novos comportamentos. Merece destaque o fato de que, já nos primeiros anos de vida, mesmo antes de iniciado o processo de alfabetização, as crianças já identificam produtos por suas logomarcas, associando a eles as informações vistas nas propagandas de televisão. Como nos ensina o saudoso Paulo Freire, "a leitura

5. CITELLI, Adílson Odair. Escola e meios de massa. In: ibidem, p. 19.

6. FREIRE, Paulo. A importância do ato de ler: em três artigos que se completam. 43. ed. São Paulo: Cortez, 2002. p. 11. (Questões da Nossa Época, n. 13). do mundo precede a leitura da palavra" ${ }^{6}$, com a percepção, o reconhecimento e a compreensão do universo circundante, que se amplia logo com os primeiros passos e não pára mais de crescer durante toda a existência da pessoa, motivada por sua curiosidade em desvendar os segredos da vida, transformando - com suas práticas - o mundo, ressignificando seus contextos.

Diante do fascínio exercido pela programação televisiva, incisivamente sobre crianças e adolescentes, e dos desafios que cercam o sistema educacional neste 
início de século, principalmente para a proposição de alternativas que visem instaurar novas formas de relacionamento entre todos os atores do processo de educação formal, ou seja, educandos e educadores, e também entre o espaço educativo e as escolas paralelas, urge considerar a possibilidade apresentada pelo professor Guillermo Orozco Gomez e seguir o exemplo do Chile, onde "os professores e a escola, como instituição educativa, foram assumindo um papel muito mais inteligente e ativo, mais propositivo como agentes mediadores entre os MCM e os estudantes"7. Assim, deve-se: aproveitar, em vez de desprezar, as inúmeras aprendizagens que ocorrem além dos muros da instituição escolar; atuar decisivamente na orientação da enorme quantidade de informações que cada educando recebe diariamente; possibilitar a ressignificação dos conteúdos das mensagens; despertar para a oportunidade de uso das potencialidades dos meios de comunicação de massa; e ampliar o diálogo com outras formas discursivas, tornando-as aliadas no processo formativo dos sujeitos, cidadãos - e consumidores - de hoje e de amanhã.

\section{VIVA A ESCOLA... VIVA!}

Ratificando o privilégio dos ambientes escolares - que se mantêm como um dos últimos espaços públicos em uma sociedade cada vez mais marcada pela individualidade e pela solidão - e o papel vital da sala de aula nos processos educativos formais, com destaque para a pluralidade discursiva que pode, e deve, transitar por aquele ambiente, há uma miríade de possibilidades envolvendo a interface comunicação/educação, para programas, projetos e iniciativas que busquem a redução das desigualdades sociais mediante maior democratização do acesso - quantitativo e qualitativo - dos cidadãos à informação. Nessa perspectiva, que se reforça pelo crescente interesse sobre a citada inter-relação: “[...] compreenda-se a existência de um conjunto de reflexões e ações voltadas à educação formal, informal e não-formal, ao ensino presencial e a distância que envolvem temas que vão das leituras críticas dos meios às experiências com produção, pelos alunos, quer de materiais jornalísticos impressos, quer de programas audiovisuais, até os desafios impostos pelas novas tecnologias com base na informática"

Assim, por meio do real envolvimento de todos os sujeitos comprometidos com a necessidade de transformação nas práticas pedagógicas, e que anseiam por uma escola viva diante das vozes do mundo, não se pode permitir que os debates e ações que visem aproximar as novas tecnologias, os meios de comunicação e as instituições escolares sejam tratados como tendência passageira ou usados apenas como chamariz na tentativa de ampliar a clientela da escola; mas sim propiciem um repensar sobre a escola como espaço mediador onde se cruzam as novas formas de ver, de sentir e de compreender o mundo contemporâneo, onde se encontram as novas linguagens e as constantes transformações das sociedades pós-modernas.
7. OROZCO GOMEZ, Guillermo. Professores e meios de comunicação: desafios, estereótipos. Comunicação \& Educação. São Paulo: CCA/ECA-USP/ Moderna, n. 10, p. 63, set./dez. 1997. Grifo do autor.

8. CITELLI, Adílson. Comunicação e educação: aproximações. In: BACCEGA, Maria Aparecida (Org.). Gestão de processos comunicacionais. São Paulo: Atlas, 2002. p. 104. 
Resumo: O presente texto ressalta a relevância do papel da instituição escolar na sociedade contemporânea, destacando, porém, alguns desafios que cercam os educadores neste novo milênio, principalmente quanto à necessidade de reconhecimento e de aproveitamento das inúmeras aprendizagens que ocorrem além dos muros da instituição escolar, aproximando o discurso didático-pedagógico de linguagens institucionalmente não-escolares.

Palavras-chave: educação, meios de comunicação de massa, televisão, escola, pós-modernidade.
The present text focuses in the important role of schools in post-modern society, pointing out some challenges that affect educators in this new millennium, mainly concerning the recognition and the best use of the various learning process which takes place beyond schools limits, nearing the didatico-pedagogical speech and non-schoolars languages.

Keywords: education, mass media, television, school, post-modernity. 